\title{
A Study on the Mechanism of Deviation between the Growth Rate of Economy and Electricity Consumption
}

\author{
Wu Shanshan ${ }^{1}$ \\ ${ }^{1}$ State Grid Energy Research Institute, \\ Beijing, China
}

\author{
Shan Baoguo ${ }^{1}$ \\ ${ }^{1}$ State Grid Energy Research Institute, \\ Beijing, China
}

\begin{abstract}
For a long time, electricity demand is regarded as the "barometer" of the economy. Electricity consumption growth becomes one of the three major indicators of Keqiang Index, as it could pre-reflect the economic growth. However, since 2015, China's economic growth and electricity demand has deviated from economic growth of China. This paper analyzes the causes of "deviation" from three angles: industry, sub-industry and product, and then draw the conclusion and forward trend.
\end{abstract}

Keywords: Electricity consumption, Economic growth, Deviation.

\section{Introduction}

Electricity is the "barometer" of economic development. For a long time, there is a very strong correlation between the growth rate of economic development and electricity demand. The correlation coefficient was 0.997 between the years of 1952 to 2011. From 2012, this relationship is decreasing, with the coefficient dropped 1.4 percentage points. The deviation between economic growth rate and electricity consumption growth rate is more and more obvious from 2012. The economic growth rate dropped from $8 \%$ in the first quarter of year 2012 to $7 \%$ in the first quarter of year 2015 , as the electricity consumption growth rate decreased from $6.8 \%$ to $0.8 \%$. That is, the difference of economic and electricity consumption growth rate expanded from 1.2 to 6.2 percentage points.

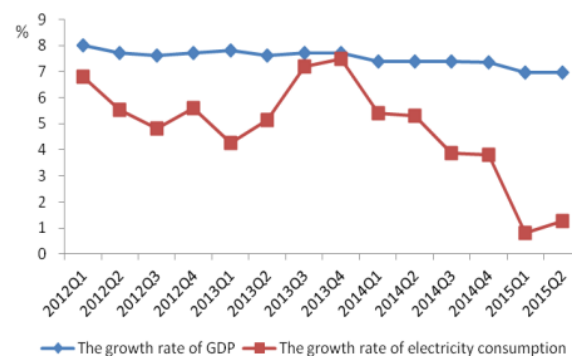

Fig. 1: The growth rate of GDP and electricity consumption
The deviation is clearer in the industry aspect, especially in high energy consuming industries. Take the ferrous metal smelting and rolling processing industry (hereinafter to be referred as ferrous-metal industry) and non metallic mineral products industry (hereinafter to be referred as non-metallic industry) for example.

The electricity consumption of ferrous-metal industry was decreased in every quarter of 2012, while the added value was still maintained a high growth rate of around $9 \%$. In the first quarter of 2015, its added value growth rate obviously dropped 8.4 percentage points than the same period of last year, while the electricity consumption only decreased 2.0 percentage points.

The electricity consumption of non-metallic industry was decreased in the first three quarters of 2012, while the added value was still maintained a high growth rate of around $14 \%$. In the first quarter of 2015 , its added value growth rate obviously dropped 10 percentage points than last year, while the electricity consumption only decreased 1.7 percentage points.

This paper analyzes the relationship and mechanism between the growth rate of economy and electricity consumption. Then, we will explain the deviation of these two variables.

\section{The mechanism of deviation between the growth rate of economy and electricity consumption}

In China, the industrial added value accounted for about 36 percent of GDP, while the proportion of its electricity consumption is up to $70 \%$. That is, industrial electricity is a major impact factor of the power use. In first 4 months of 2015 , the growth rate of above-scale industrial added value was $6.2 \%$, while the growth rate of its electricity consumption was only $-0.8 \%$, the lowest since October 2009. The deviation of added value and electricity consumption of industry is the mainly reason of the deviation of economy and power use.

The output decreasing of high energy consuming products lead to industrial electricity consumption negative growth. The Industrial electricity consumption growth rate in first four months of 2015 was $-9.6 \%,-4.1 \%,-1.1 \%$, respectively, mainly due to the sustained decrease of 23 kinds of products, such as crude steel, cement, plate glass, 
caustic soda and other major product. Take the ferrousmetal and non-metallic industries for example as well. There was a strong relationship between growth rate of the pig iron output and the ferrous-metal industry electricity consumption from January 2010 to April 2015, with the correlation coefficient and intercept were 1.24 and 0.67 , respectively. That is, when the pig iron output growth dropped $1 \%$, ferrous metal industry growth rate of electricity consumption fell 1.24 percentage points. There was also a strong relationship between the growth rate of cement output and the non-metals industry electricity consumption from January 2010 to April 2015, with the correlation coefficient and intercept were 0.82 and 0.81 , respectively. That is, when the pig iron output growth dropped $1 \%$, ferrous metal industry growth rate of electricity consumption fell 0.82 percentage points.

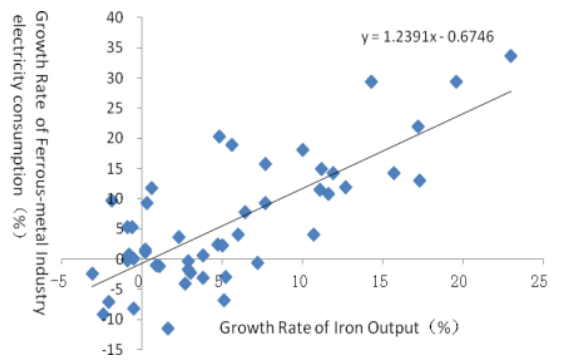

Figure 2: The relationship between growth rate of the pig iron output and the ferrous-metal industry electricity consumption

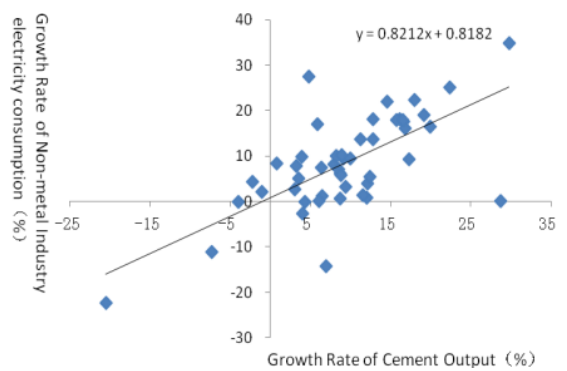

Figure 3: The relationship between the growth rate of cement output and the non-metals industry electricity consumption

There is a deviation between some high energy products output and its industrial added values. In 2015, some high energy products output sustained decreased, such as pig iron, crude steel, cement, flat glass, caustic soda and other production; while the industrial added values continued increased, such as ferrous-metal, non-metals and chemical industry. Take the ferrous-metal and non-metallic industries for example as well.

From January 2010 to April 2015, the correlation coefficient and intercept between growth rate of pig iron output and the ferrous-metal industry electricity consumption were 1.24 and 0.67 , respectively. Although there was a positive correlation, the intercept was significantly greater than zero, which lead to the trend line is distributed in first and second quadrants. That is, when the ferrous-metal industry added value increased, the iron output would grow as well; when the iron output decreased, ferrous-metal industry added value would also increased with rate of $7 \%$.

From January 2010 to April 2015, the correlation coefficient and intercept between the growth rate of cement output growth and the non-metal industry electricity consumption were 0.49 and 9.1 , respectively. It showed when the non-metal industry added value increased $1 \%$, the cement output would improve $0.49 \%$ as well; when the cement output decreased, non-metal industry added value would also increased with rate of $9 \%$.

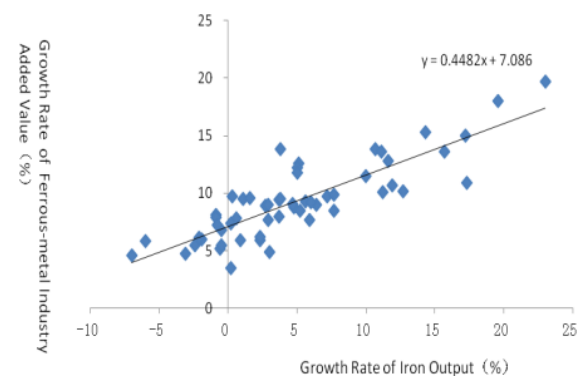

Figure 4: The relationship between growth rate of the pig iron output and the ferrous-metal industry added value

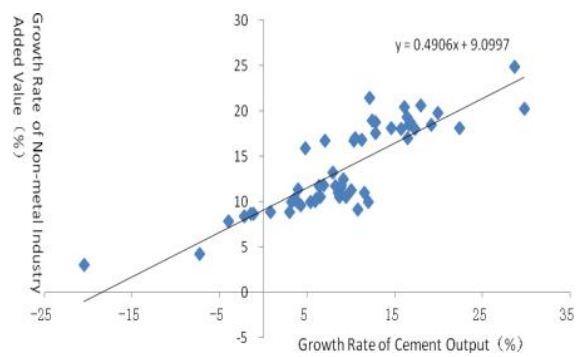

Figure 5: The relationship between the growth rate of cement output and the non-metals industry added value

\section{The reason of deviation between the growth rate of economy and electricity consumption}

The structural adjustment on products three levels of industry, enterprises and product is the main reason of the deviation between the growth rate of economy and electricity consumption. During the structural adjustment of industry, the growth rate of high energy consuming industry fell more significantly than any other industries, while the growth rate of high technology consuming industry accelerated more significantly. This trend leads to a significant decline in industrial electricity consumption. During the first four months, the added value growth rate of ferrous-metal, nonferrous-metal, non-metals and chemical industry dropped 2.5、3.1、1.3 and 3.6 percentage points; 
the added value growth rate of transportation equipment manufacturing, computer communications manufacturing and other manufacturing industry increased 3.1, 0.2 and 7.4 percentage points. During the structural adjustment of enterprises, due to the lack of market demand, product prices fell sharply, and then the loss of enterprises continued to intensify. In this process, only the advanced technology enterprises with low energy consumption could survive. Take the ferrous-metal industry for example. From January to April of 2015, the loss of enterprises increased by $11.9 \%$, resulting in a sharp decline in the number of 451 companies. The existing enterprises, such as Hubei, Chengdu and other state-owned steel company have already begin to shut down the old beltline and do some transition projects. During the structural adjustment of products, due to the changes in the market environment, the production of enterprises, such as Huaxin, Jidong, building materials and other a plurality of cement enterprises, are more inclined to extend the industrial chain, to do some deep processing for increasing added value, and eliminating high energy consumption product. At the same time, the cement, nuclear power, cement, cement and other special road cement will become the focus of the development of large enterprises.

\section{Conclusions}

The trend of industry growth and product output growth is consistent. The deviation between growth rate of industry added value and products output caused by adjustment from three levels is the fundamental reason of deviation between growth rate of industry electricity consumption and industry added value is the fundamental reason, which leads to the deviation between growth rate of economy and electricity consumption.

According to the current economic trends and the direction of China's policy regulation, structure optimization of industry, enterprise and product is the trend of the times. Therefore, the deviation between growth rate of economy and electricity consumption will become the "new normal" in the future.

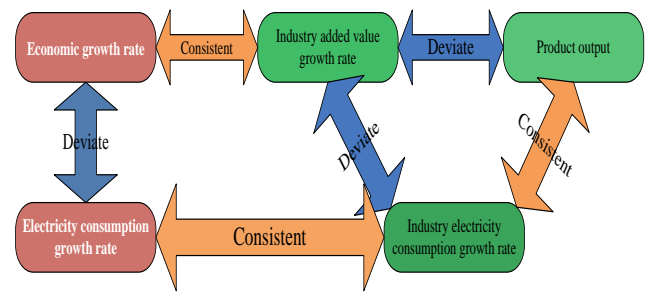

Figure 6: Logical analysis chart of the deviation between growth rate of economy and electricity consumption

\section{References}

[1] XU Min-jie, HU Zhao-guang, SHAN Bao-guo, WU Jun-yong, "Analysis on influencing factors of electricity demand by using interpretative structural modeling," Electric Power, vol.42 (4), pp. 1-5, 2009.

[2] TAN Xian-dong, SHAN Bao-guo, XU Min-jie, "Simulation of mid-long term demand for electricity based on input-output method," Electric Power, vol.43 (1), pp. 1-4, 2010.

[3] TAN Xian-dong, SHAN Bao-guo, "Study on the Relationship between the "Troika" and the Electricity Demand," Energy Technology and Economics, vol.22 (6), pp. 25-27, 2010.

[4] SHANBao-guo, HUZhao-guang, "Analysison thevariation ofelectricityintensityin China," Electric Power, vol.40 (9), pp. 11-14, 2007.

[5] http://www.ccement.com/news/content/7921192964572 .html. 